Research Article

\title{
Adjusting LQG with Noise Signals, PID Controller for Acrobot System
}

\author{
Nguyen Cong Danh \\ The Independent Researcher, Phnom Penh, Cambodia \\ Correspondence should be addressed to Nguyen Cong Danh; congdanh.ptithcm@gmail.com
}

Received 21 June 2021; Revised 12 August 2021; Accepted 13 August 2021; Published 27 August 2021

Academic Editor: Jose de Jesus Rubio

Copyright () 2021 Nguyen Cong Danh. This is an open access article distributed under the Creative Commons Attribution License, which permits unrestricted use, distribution, and reproduction in any medium, provided the original work is properly cited.

\begin{abstract}
Acrobot is a robotic system that is actuated to achieve a certain degree through a controller and/or motion motors. In order to control acrobot in a given position, the designers have to come up with appropriate algorithms. In fact, input signals into the system are affected by noise signals. Therefore, it is necessary to remove noisy signals. In this paper, a method to control the balance under the influence of noise signals affecting the system (LQG) is proposed. Through acrobot's equations of motion, the system is linearized to facilitate the use of the above regulator for positions around the equilibrium point. The role of a Kalman filter of an LQG regulator is also depicted. Besides, a PID controller was used to survey this system as a comprehensive assessment of the effectiveness of control methods for acrobot. As acrobot stability surveys are rare in recent years according to the data referenced below, this paper is useful for acrobot control purposes and can serve as an important database for the application of acrobots in practice. Simulations are performed on Matlab.
\end{abstract}

\section{Introduction}

Nowadays, controllers such as PID, fuzzy, and sliding mode are applied to control all kinds of robots. This is a strong step toward helping robots achieve the requirements set out. For the acrobot system, the algorithms to control the balance are always focused on the selection of controllers. Modern robots are controlled with classical algorithms and genetic algorithms [1] and intelligent algorithms [2] where noise signals are not taken into account. In $[1,2]$, it is possible that the noise signals considered are negligible. Algorithms can be widely applied in the future such as selfdriving subways, self-driving fighter planes, and so on. In this paper, a method to control the balance under the influence of noise signals affecting the system (LQG) is proposed. In the section presented below, the role of Kalman filter to form an LQG regulator is depicted. This method will optimally control a system in the presence of unwanted signals.

Other systems have similar motion characteristics like acrobot, including pendulum, inverted pendulum [3], and reaction wheel inverted pendulum [4], which are nonlinear systems such as single-input multi-output (SIMO). In SIMO systems, the designers have a lot of difficulty in determining the exact position that has been placed for the pendulum according to the requirements. The flexible structured models using the algorithms in [5-7] are interesting experiences. Robustness in the optimal control method based on multivariable control design [8] is a new topic. Some extensions of loop transfer recovery [9] for flexible structures are regarded as a promising application. Loop recovery and robust state estimate feedback designs [10] for robotic systems are always welcome. Loop transfer recovery with nonminimum phase zeros [11] for electric motors is also interesting work. The LQG/LTE procedure for multivariable feedback design [12] is necessary to experience the application of any particular model. Multivariable feedback design concepts for a classical/ modern synthesis [13] are useful as a reference for setting up newer algorithms. Feedback property of multivariable systems [14] is an interesting subject for its application to a system with a flexible structure. It is necessary to develop 
algorithms [15-19] so that they are more in line with today's trend. Based on [20-23], the author applied algorithms [20-23] for robot models. The author used modern algorithms such as neural control, adaptive fuzzy control, and sliding fuzzy control to control the model [24-27], and efficiency levels of the above control methods are presented in detail. This paper focuses on the process of investigating the effectiveness of using two control methods as mentioned in the problem. The purpose of this is to cater to practical requirements and considerations in the selection of control methods. Acrobot is a new automated system, which has many utilities in life. The aforementioned studies have not dealt with acrobots in detail, so it is always an interesting experience to investigate the properties of acrobot systems. The acrobot system is described by a link between link 1 and link 2 as shown below (Figure 1).

\section{Dynamic Equation of Model System}

It is necessary to establish a mathematical equation that describes the motion of any model. Through these equations of motion, controllers can be installed inside the system. They will be connected to the system via wireless devices or wired devices. Usually, control systems have one or more controllers connected to the systems by wired devices. With the successful establishment of the mathematical equations, the author calculated the values of $K$ in LQG regulator. For example, acrobot or an inverted pendulum is described by mathematical equations. Acrobot has a similar structure to Pendubot [3], but the difference between the two lies in their control joint positions. The two-dimensional coordinate system: $O x$ and $O y$, is depicted in Figure 1 [28].

Parameters of the acrobot system are listed in Table 1. Variables are $q_{1}, q_{2}$, and $\tau_{2}$, where $q_{1}$ and $q_{2}$ are output signals and $\tau_{2}$ is input signal. The selection of variables was based on the structure of the system as shown in Figure 1. Variables have unknown values. In the process of designing controllers for these systems, readers can better understand the nature of the relationships between input signals and output signals through voltage signals and the torque of an electric motor. That is, these values do not have a specific value during the analysis, but their influence on the system is important.

In Figure 1, the $x$-axis of the Cartesian coordinate system was chosen to be the reference level of zero potential energy. Letting $X_{i}=\left[X_{i}^{x}, X_{i}^{y}\right]^{T} \in R^{2}$ be the absolute position of the COM of the $i^{\text {th }}$ link gives [24]

$$
\begin{aligned}
& X_{1}=\left[\begin{array}{l}
L c_{1} \sin q_{1} \\
L c_{1} \cos q_{1}
\end{array}\right], \\
& X_{2}=\left[\begin{array}{l}
L_{1} \sin q_{1}+L c_{2} \sin \left(q_{1}+q_{2}\right) \\
L_{1} \cos q_{1}+L c_{2} \cos \left(q_{1}+q_{2}\right)
\end{array}\right] .
\end{aligned}
$$
$V(q)$ :

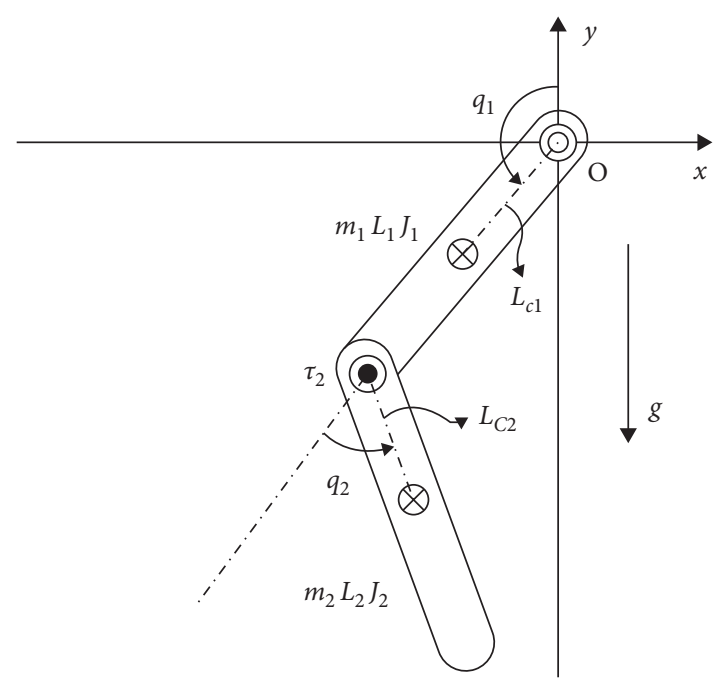

(a) Passive Joint

(-) Active Joint

$\bigotimes$ Center of Mass

Figure 1: Mathematical model of acrobot system.

$$
\begin{aligned}
& K(q, \dot{q})=\frac{1}{2} \sum_{i=1}^{2}\left[m_{i} \dot{X}_{i}^{2}+J_{1} \dot{q}_{1}^{2}+J_{2}\left(\dot{q}_{1}+\dot{q}_{2}\right)^{2}\right], \\
& K(q, \dot{q})=\frac{1}{2}\left[\begin{array}{ll}
\dot{q}_{1} & \dot{q}_{2}
\end{array}\right] M\left(q_{2}\right)\left[\begin{array}{l}
\dot{q}_{1} \\
\dot{q}_{2}
\end{array}\right],
\end{aligned}
$$

where

$$
\begin{aligned}
M\left(q_{2}\right) & =\left[\begin{array}{cc}
a_{1}+a_{2}+2 a_{3} \cos \left(q_{2}\right) & a_{2}+a_{3} \cos \left(q_{2}\right) \\
a_{2}+a_{3} \cos q_{2} & a_{2}
\end{array}\right], \\
& \left\{\begin{array}{l}
a_{1}=m_{1} L_{c_{1}}^{2}+m_{2} L_{1}^{2}+J_{1}, \\
a_{2}=m_{2} L_{c_{2}}^{2}+J_{2}, \\
a_{3}=m_{2} L_{1} L_{c_{2}} \\
a_{4}=\left(m_{1} L_{c_{1}}+m_{2} L_{1}\right) g, \\
a_{5}=m_{2} L_{c_{2}} g .
\end{array}\right.
\end{aligned}
$$

Considering that friction is very small, the author used Lagrangian of acrobot; then, the dynamic equation of the mechanical system is

$$
V(q)=m_{1} g X_{1}^{y}+m_{2} g X_{2}^{y}=a_{4} \cos q_{1}+a_{5} \cos \left(q_{1}+q_{2}\right),
$$

$$
\frac{d}{d t}\left[\frac{\partial L(q, \dot{q})}{\partial \dot{q}_{i}}\right]-\frac{\partial L(q, \dot{q})}{\partial q_{i}}=\dot{\tau}_{i}, \quad i=1,2,
$$

where $L(q, \dot{q})=K(q, \dot{q})-V(q)$ and $\tau_{1}=0$. Equation (5) is equivalent to

$$
M\left(q_{2}\right) \ddot{q}+C(q, \dot{q}) \dot{q}+G(q)=\left[\begin{array}{c}
0 \\
\tau_{2}
\end{array}\right],
$$


TABle 1: Parameters of model.

\begin{tabular}{|c|c|}
\hline Parameters and variables & Description \\
\hline$q_{1}$ & Angle of link 1 \\
\hline$q_{2}$ & Angle of link 2 \\
\hline$\dot{q}_{1}$ & Angular velocity of link 1 \\
\hline$\dot{q}_{2}$ & Angular velocity of link 2 \\
\hline$m_{1}$ & Mass of link 1 \\
\hline$L_{1}$ & Length of link 1 \\
\hline$L_{c 1}$ & Distance from passive joint to the center of mass of link 1 \\
\hline$m_{2}$ & Mass of link 2 \\
\hline$L_{2}$ & Length of link 2 \\
\hline$L_{c 2}$ & Distance from active joint to the center of mass of link 1 \\
\hline$J_{1}$ & Moment of inertia of link 1 \\
\hline$J_{2}$ & Moment of inertia of link 2 \\
\hline$g$ & Gravitational acceleration \\
\hline$\tau_{2}$ & Torque applied to active joint \\
\hline
\end{tabular}

where

$$
\begin{aligned}
q & =\left[\begin{array}{ll}
q_{1} & q_{2}
\end{array}\right]^{T}, \\
C(q, \dot{q}) & =\left[\begin{array}{cc}
-a_{3} \dot{q}_{2} \sin q_{2} & -a_{3}\left(\dot{q}_{1}+\dot{q}_{2}\right) \sin q_{2} \\
a_{3} \dot{q}_{1} \sin q_{2} & 0
\end{array}\right], \\
G(q) & =\left[\begin{array}{c}
-a_{4} \sin q_{1}-a_{5} \sin \left(q_{1}+q_{2}\right) \\
-a_{5} \sin \left(q_{1}+q_{2}\right)
\end{array}\right] .
\end{aligned}
$$

State-space equations are created as

$$
x=\left[\begin{array}{llll}
x_{1} & x_{2} & x_{3} & x_{4}
\end{array}\right]^{T}=\left[\begin{array}{llll}
q_{1} & \dot{q}_{1} & q_{2} & \dot{q}_{2}
\end{array}\right]^{T} .
$$

Let

$H(q, \dot{q})=\left[H_{1}(q, \dot{q}) H_{2}(q, \dot{q})\right]^{T}:=C(q, \dot{q}) \dot{q}+G(q)$.

Dynamic equation (6) can be described as

$$
\dot{x}=f(x)+g(x) \tau_{2},
$$

where

$$
\left\{\begin{array}{l}
f(x)=\left[\begin{array}{llll}
x_{2} & P(1,1) & x_{4} & P(2,1)
\end{array}\right]^{T}, \\
g(x)=\left[\begin{array}{llll}
0 & Z(1,1) & 0 & Z(2,1)
\end{array}\right]^{T} .
\end{array}\right.
$$

$P(i, j)$ and $Z(i, j)$ are matrices having the $i^{\text {th }}$ row and $j^{\text {th }}$ column of $P$ and $Z$. Therefore, $P$ and $Z$ are determined as

$$
\left\{\begin{array}{l}
P=-M^{-1}\left(q_{2}\right)\left[\begin{array}{l}
H_{1}(q, \dot{q}) \\
H_{2}(q, \dot{q})
\end{array}\right] \\
Z=M^{-1}\left(q_{2}\right)\left[\begin{array}{l}
0 \\
1
\end{array}\right] .
\end{array}\right.
$$

The establishment of acrobot's equation of state is based on the values of Table 2 .

The state variable equations of the system are described as follows:
TABle 2: Parameters of the acrobot system.

\begin{tabular}{lc}
\hline Parameters & Values \\
\hline$m_{1}$ & $0.8 \mathrm{~kg}$ \\
$L_{1}$ & $0.18 \mathrm{~kg}$ \\
$L_{c 1}$ & $0.11 \mathrm{~m}$ \\
$m_{2}$ & $0.2 \mathrm{~kg}$ \\
$L_{2}$ & $0.18 \mathrm{~m}$ \\
$L_{c 2}$ & $0.09 \mathrm{~m}$ \\
$J_{1}$ & $0.0022 \mathrm{~kg} \mathrm{~m}^{2}$ \\
$J_{2}$ & $0.00054 \mathrm{~kg} \mathrm{~m}^{2}$ \\
\hline
\end{tabular}

$$
\left\{\begin{array}{l}
\dot{x}=A x+B u, \\
c=C x+D x
\end{array}\right.
$$$$
A=\left[\begin{array}{cccccc}
\frac{\partial f_{1}}{\partial x_{1}} & \frac{\partial f_{1}}{\partial x_{2}} & \frac{\partial f_{1}}{\partial x_{3}} & \frac{\partial f_{1}}{\partial x_{4}} & \cdots & \frac{\partial f_{1}}{\partial x_{n}} \\
\frac{\partial f_{2}}{\partial x_{1}} & \frac{\partial f_{2}}{\partial x_{2}} & \frac{\partial f_{2}}{\partial x_{3}} & \frac{\partial f_{2}}{\partial x_{4}} & \cdots & \frac{\partial f_{2}}{\partial x_{n}} \\
\cdots & \cdots & \cdots & \cdots & \cdots & \ldots \\
\frac{\partial f_{n}}{\partial x_{1}} & \frac{\partial f_{n}}{\partial x_{2}} & \frac{\partial f_{n}}{\partial x_{3}} & \frac{\partial f_{n}}{\partial x_{4}} & \cdots & \frac{\partial f_{n}}{\partial x_{n}}
\end{array}\right],
$$

$$
B=\left[\begin{array}{c}
\frac{\partial f_{1}}{\partial u} \\
\frac{\partial f_{2}}{\partial u} \\
\cdots \\
\frac{\partial f_{n}}{\partial u}
\end{array}\right] .
$$


With the above parameters and matrices $A$ and $B$ of the state-space model, $G_{1}(s), G_{2}(s), G_{3}(s)$, and $G_{4}(s)$ are calculated:

$$
\begin{aligned}
& A=\left[\begin{array}{cccc}
0 & 1 & 0 & 0 \\
70.6961 & -19.6783 & 0 & 0 \\
0 & 0 & 0 & 1 \\
-94.9903 & 130.9458 & 0 & 0
\end{array}\right], \\
& B=\left[\begin{array}{c}
0 \\
-185.7355 \\
0 \\
927.3017
\end{array}\right], \\
& C=\left[\begin{array}{llll}
1 & 0 & 0 & 0 \\
0 & 1 & 0 & 0 \\
0 & 0 & 1 & 0 \\
0 & 0 & 0 & 1
\end{array}\right], \\
& D=0 .
\end{aligned}
$$

Transfer function of acrobot:

$$
\begin{aligned}
& G_{1}(s)=\frac{-185.7}{s^{2}+19.68 s-70.7}, \\
& G_{2}(s)=\frac{927.3 s^{2}-6074 s-4.791 \times 10^{4}}{s^{4}+19.68 s^{3}-70.7 s^{2}}, \\
& G_{3}(s)=\frac{-185.7 s}{s^{2}+19.68 s-70.7}, \\
& G_{4}(s)=\frac{927.3 s^{2}-6074 s-4.791 \times 10^{4}}{s^{3}+19.68 s^{2}-70.7 s} .
\end{aligned}
$$

\section{LQG Regulator}

LQG Regulator (linear quadratic Gaussian) is used for optimal control of a system while noise signals "affect" the system. The author considered the following diagram (Figure 2).

The goal of adjusting is to stabilize the output at zero; under the influence of input white noise signals $(w)$ and noise signals due to $(v)$, the control signal is " $u$," and the equation of state is

$$
\left\{\begin{array}{l}
\dot{x}=A x+B u+G w \\
\bar{y}=C x+D u+H w+v
\end{array}\right.
$$

LQG Regulator consists of using a state feedback unit and a state estimator (Kalman filter) (Figure 3).

The quality indicator $(J)$ is used to find the state feedback matrix $K=\operatorname{lqr}(A, B, Q, R, N)$.

$$
J(u)=\int_{0}^{\infty}\left\{x^{T} Q x+2 x^{T} N u+u^{T} R u\right\} \mathrm{d} t .
$$

The control signal is $u=-K \times \widehat{x}$, and $\widehat{x}$ is inferred as

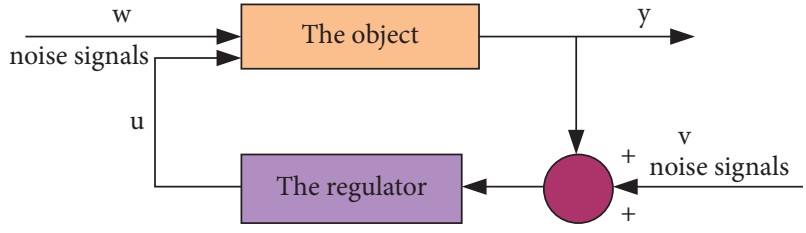

FIgURE 2: Diagram of a regulator for an object with noise signals ("v": the white noise and " $w$ ": the color noise signal).

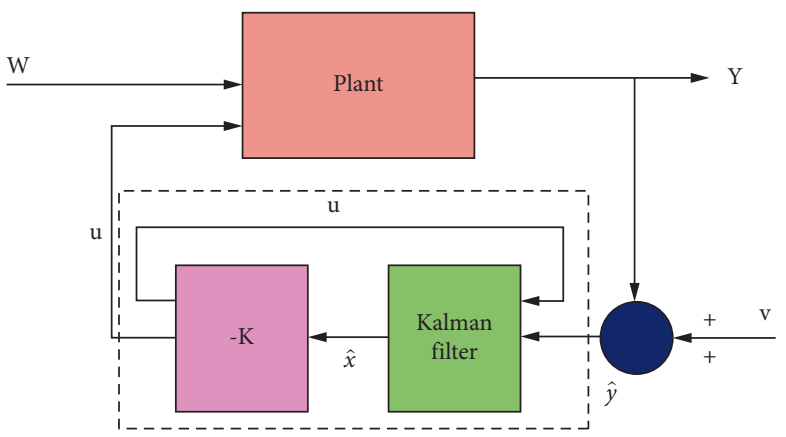

FIGURE 3: LQG regulator with noise signals (" $v$ ": the white noise and " $w$ ": the color noise signal).

$$
\dot{\bar{x}}=A \widehat{x}+B u+L(\bar{y}-C \hat{x}-D u),
$$

where " $L$ " is the Kalman gain and " $L$ " is calculated by the following commands:

$$
\begin{aligned}
{\left[k_{\text {est }}, L, P\right] } & =\operatorname{Kalman}\left(\text { sys, } Q_{n}, R_{n}, N_{n}\right), \\
{\left[k_{\text {est }}, L, P, M, Z\right] } & =\text { kalmd }\left(\text { sys, } Q_{n}, R_{n}, T_{s}\right), \\
{\left[k_{\text {est }}, L, P\right] } & =\operatorname{Kalman}\left(\text { sys, } Q_{n}, R_{n}, N_{n}, \text { sensors, known }\right), \\
{\left[k_{\text {est }}, L, P, M, Z\right] } & =\operatorname{Kalman}\left(\text { sys, } Q_{n}, R_{n}, N_{n}\right),
\end{aligned}
$$

where $Q_{n}, R_{n}$, and $T_{s}$ represent the variance of the noise signal. $E\left(w w^{T}\right)=Q_{n}, E\left(v v^{T}\right)=R_{n}, E\left(w v^{T}\right)=N_{n}$, and $k_{e s t}$ is the model of the Kalman filter.

Kalman filter calculates $\hat{x}$ to minimize the variance:

$$
P=\lim _{t \longrightarrow \infty} E\left(\{x-\hat{x}\}\{x-\hat{x}\}^{T}\right) .
$$

The equation of state for a regulator (LQG) is

$$
\frac{d}{d t} \widehat{x}=[A-L C-(B-L D)] \widehat{x}+L \bar{y},
$$

where $u=-K \hat{x}$ is created by the following commands:

$$
\begin{aligned}
& r l q g=\operatorname{lqgreg}\left(k_{\text {est }}, k\right), \\
& r l q g=\operatorname{lqgreg}\left(k_{\text {est }}, k, \text { current }\right), \\
& r l q g=\operatorname{lqgreg}\left(k_{\text {est }}, k, \text { controls }\right),
\end{aligned}
$$

where rlqg is the state-space model of a set of LQG, the output is $u$, the input is $\bar{y}$, and the state is $\hat{x}$.

Finally, the command is requested: 


$$
\begin{aligned}
& r s y s=\operatorname{reg}(\text { sys, } K, L), \\
& r s y s=\operatorname{reg}(\text { sys, } K, L, \text { sensors, known, controls). }
\end{aligned}
$$

The author established a closed system with the value of "sys" as the object model, and the value of " $K$ " is the state feedback matrix, " $L$ " is the state estimation matrix, "sensors" represent a subset of outputs, the value of " $y$ " returns the estimator, "known" represents the inputs, " $u_{d}$ " affects the estimator, and "controls" are inputs of "sys" that is used for control.

\section{Simulation Results and Discussion}

Simulation results are shown in Figures 4-35.

Diagram of the system using the LQG regulator is shown in Figures 36-39.

Diagram of the system using the PID controller is shown in Figures 40-43.

In Figures 36-39, the value of " $d$ " is a color noise signal with a spectral density of less than $10 \mathrm{rad} / \mathrm{s}$, and the value of " $n$ " is a white noise signal $E\left(n^{2}\right)=0.01$. The quality indicator is ' $J$ : $J(u)=\int_{0}^{\infty}\left(10 y^{2}+u^{2}\right) \mathrm{d} t$. The model of the object is $\dot{x}=A x+B u+B d, \bar{y}=C x+n$.

The impulse response for the closed system (highlighted in red in Figure 6) is better than that for the open system (highlighted in green in Figure 7). The value of amplitude of the oscillation of the closed system in this case is zero, and the closed system reaches a steady state. For this type of regulator, the closed system responds well. The value of amplitude of the oscillation of the open system in this case is large, and the open system does not reach a steady state.

The step response for the closed system (highlighted in blue in Figure 4) is better than that for the open system (highlighted in red in Figure 5). The value of amplitude of the oscillation of the closed system in this case is -0.6 , and the closed system reaches a steady state. For this type of regulator, the closed system responds well. Meanwhile, the open system cannot respond well. In general, for a regulator of this type, the system responds well to the presence of noisy signals.

The impulse response for the closed system (highlighted in red in Figure 10) is better than that for the open system (highlighted in blue in Figure 11). The value of amplitude of the oscillation of the closed system in this case is zero, and the closed system reaches a steady state. For this type of regulator, the closed system responds well. The value of amplitude of the oscillation of the open system in this case is large, and the open system does not reach a steady state.

The step response for the closed system (highlighted in green in Figure 8) is better than that for the open system (highlighted in green in Figure 9). The value of amplitude of the oscillation of the closed system in this case is -30 , and the closed system reaches a steady state. For this type of regulator, the closed system responds well. Meanwhile, the open system cannot respond well. In general, for a regulator of this type, the system responds well to the presence of noisy signals.

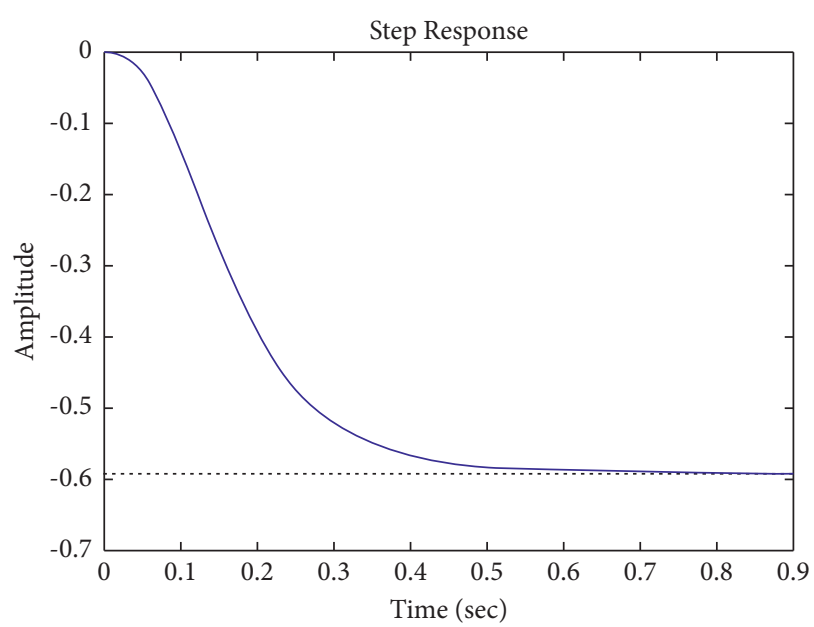

FIGURE 4: Step response of LQG regulator for the closed system “ $G_{1}(s)$."

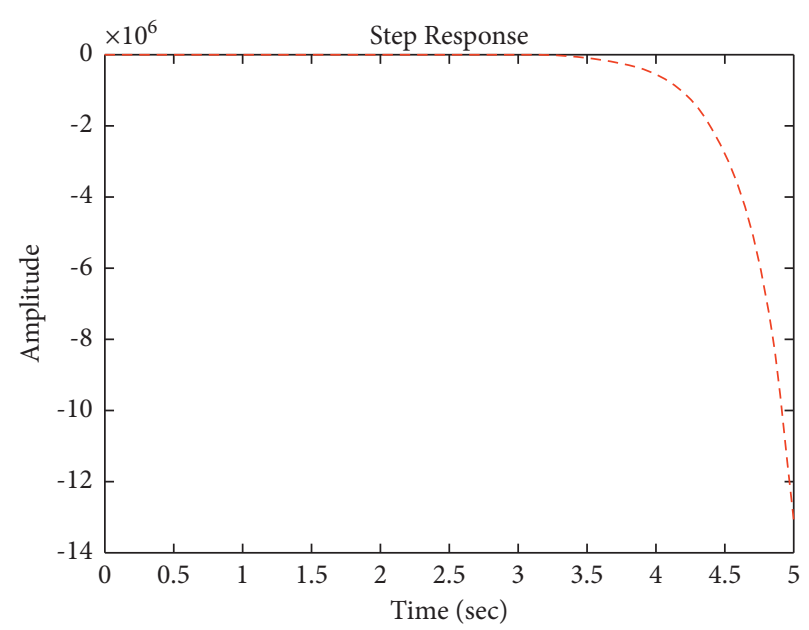

FIGURE 5: Step response of LQG regulator for the open system “ $G_{1}(s) . "$

The impulse response for the closed system (highlighted in blue in Figure 14) is better than that for the open system (highlighted in green in Figure 15). The value of amplitude of the oscillation of the closed system in this case is zero, and the closed system reaches a steady state. For this type of regulator, the closed system responds well. The value of amplitude of the oscillation of the open system in this case is large, and the open system does not reach a steady state.

The step response for the closed system (highlighted in red in Figure 12) is better than that for the open system (highlighted in red in Figure 13). The value of amplitude of the oscillation of the closed system in this case is zero, and the closed system reaches a steady state. For this type of regulator, the closed system responds well. Meanwhile, the open system cannot respond well. In general, for a regulator of this type, the system responds well to the presence of noisy signals. 


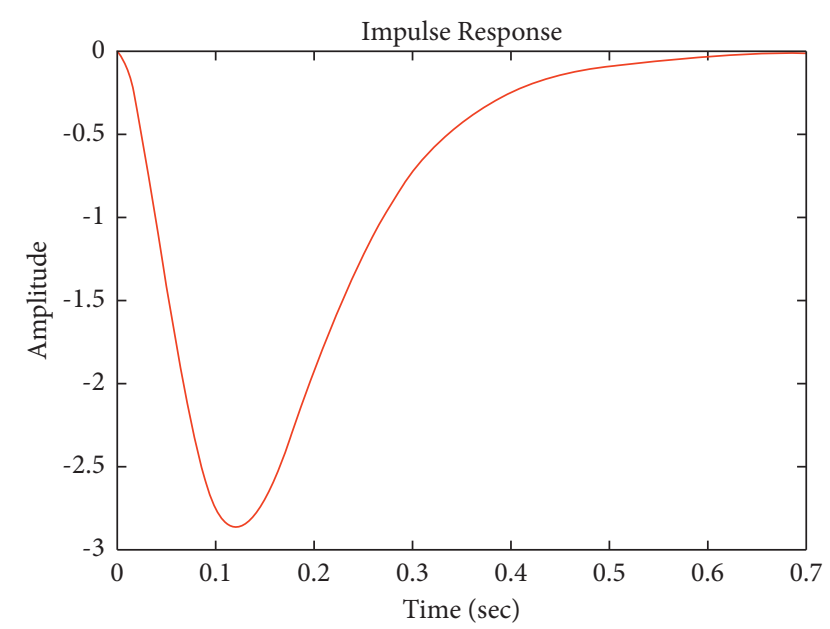

FIGURE 6: Impulse response of LQG regulator for the closed system “ $G_{1}(s)$."

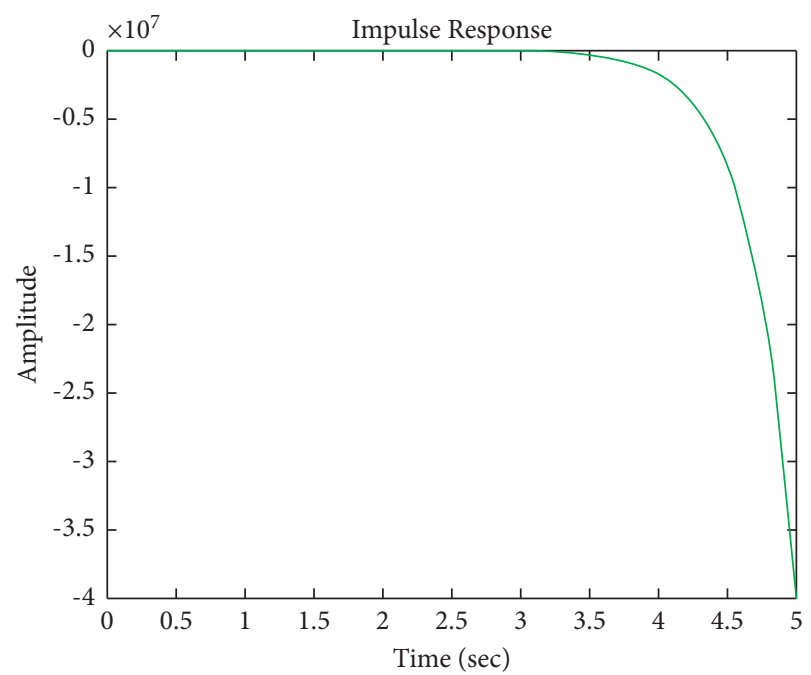

FIGURE 7: Impulse response of LQG regulator for the open system " $G_{1}(s)$."

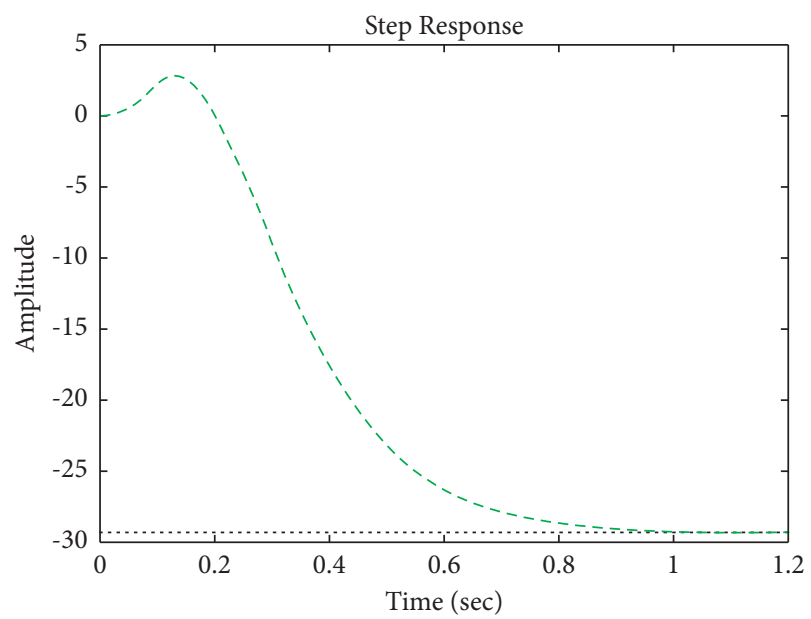

FIGURE 8: Step response of LQG regulator for the closed system " $G_{2}(s)$."

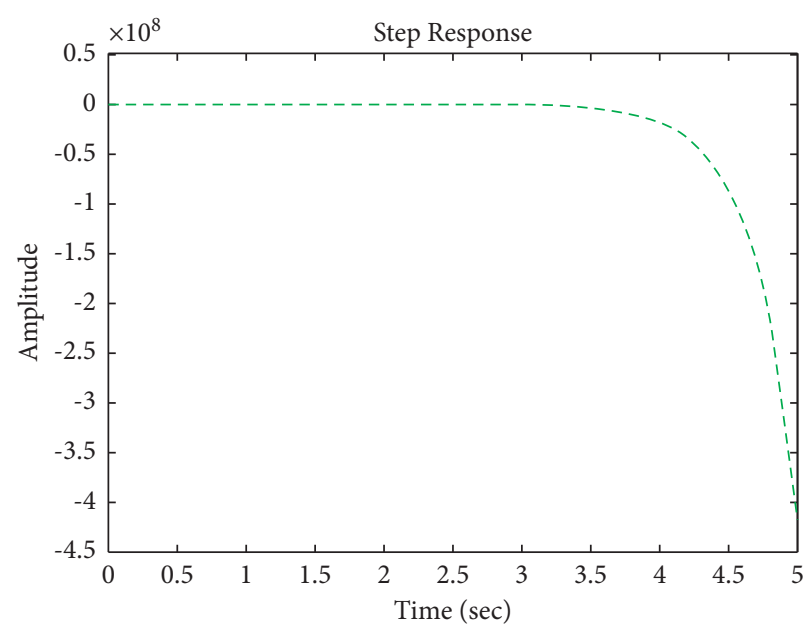

FIGURE 9: Step response of LQG regulator for the open system "G $G_{2}(s)$."

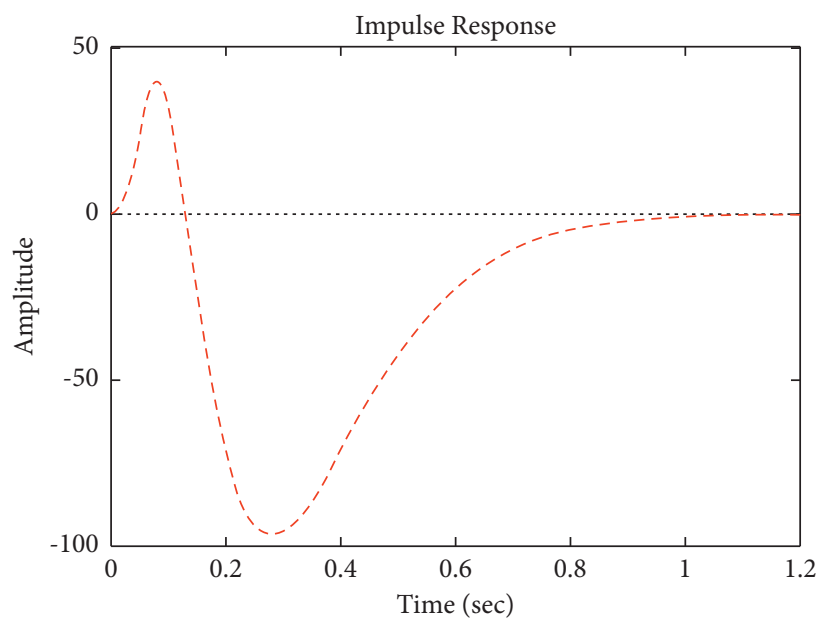

FIGURE 10: Impulse response of LQG regulator for the closed system " $G_{2}(s)$."

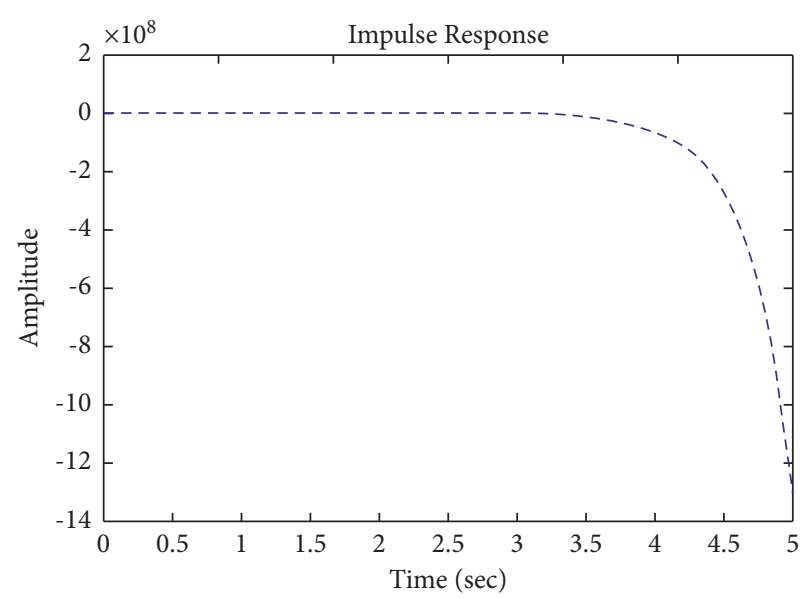

FIGURE 11: Impulse response of LQG regulator for the open system “ $G_{2}(s) . "$ 


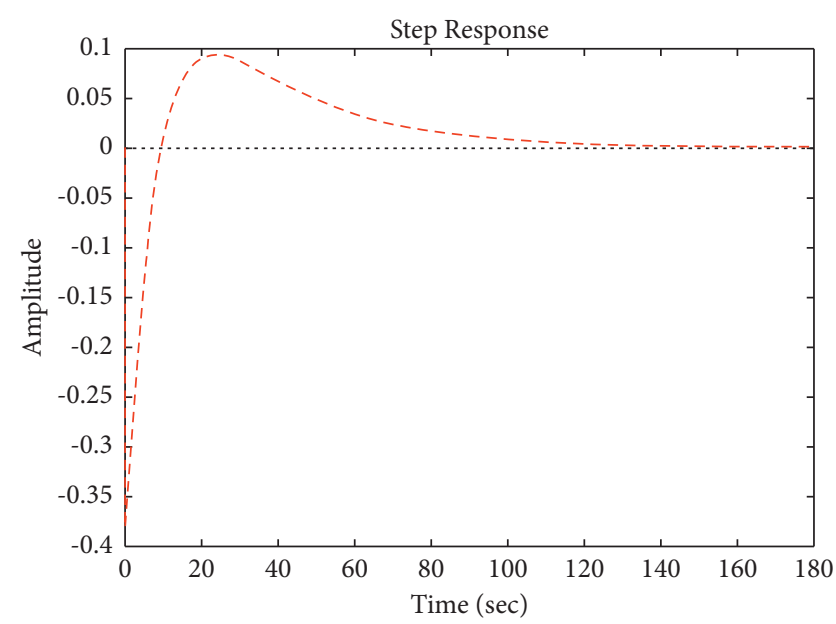

FIGURE 12: Step response of LQG regulator for the closed system " $G_{3}(s)$."

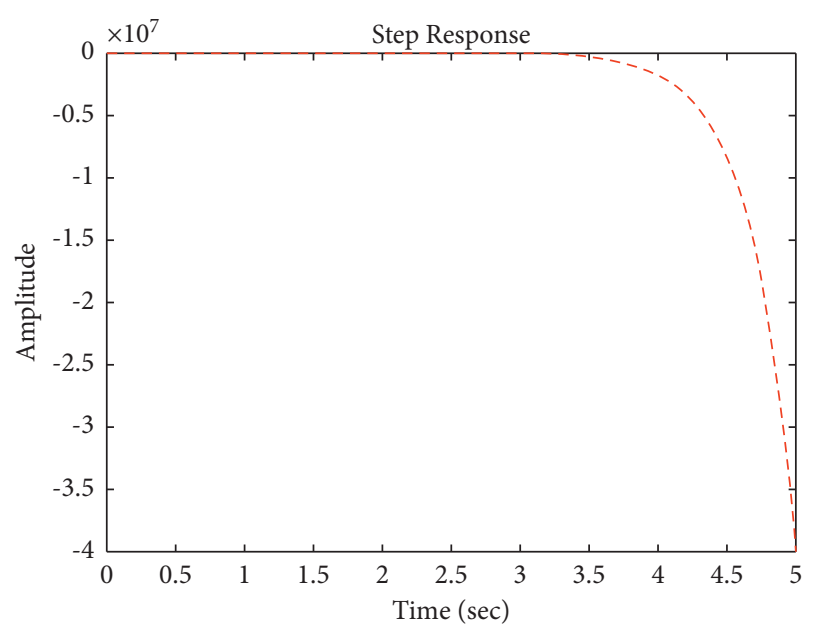

FIGURE 13: Step response of LQG regulator for the open system " $G_{3}(s)$."

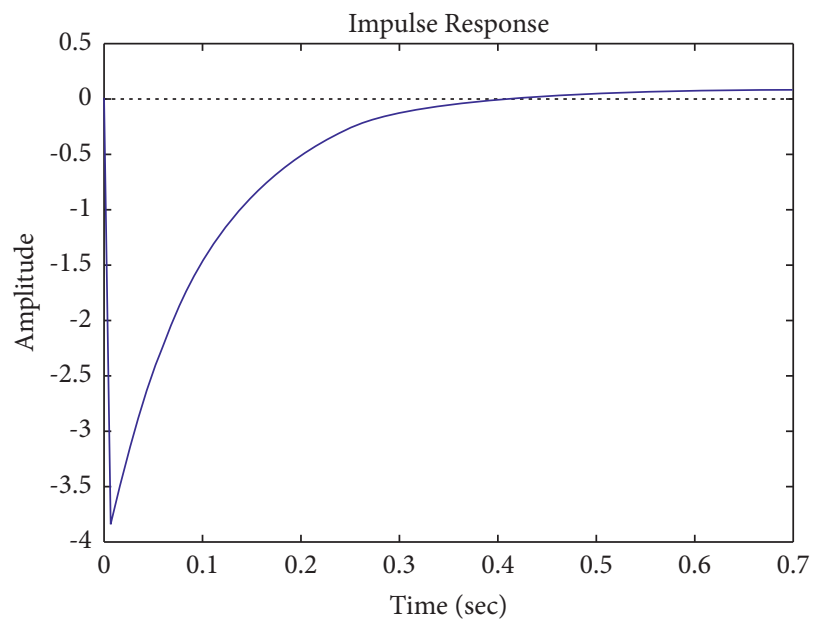

FIGURE 14: Impulse response of LQG regulator for the closed system “ $G_{3}(s)$."

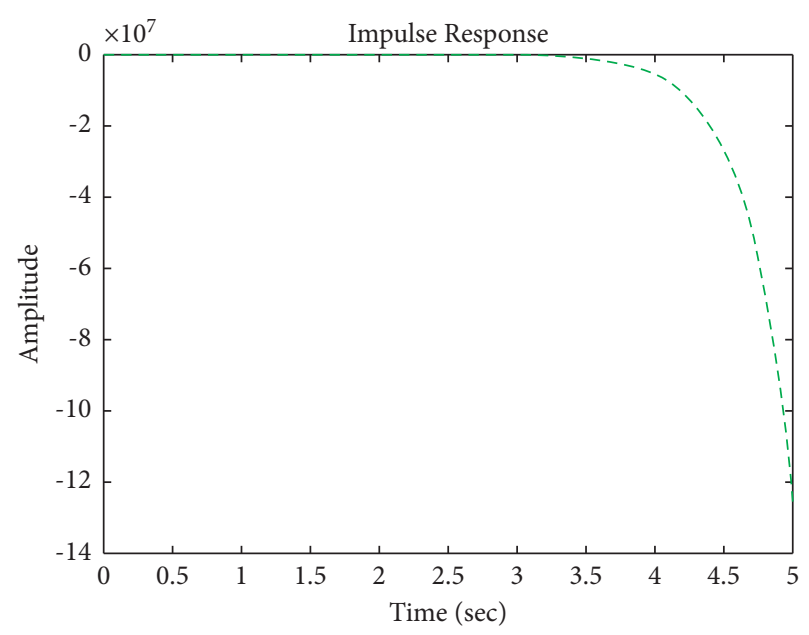

FIGURE 15: Impulse response of LQG regulator for the open system “ $G_{3}(s)$."

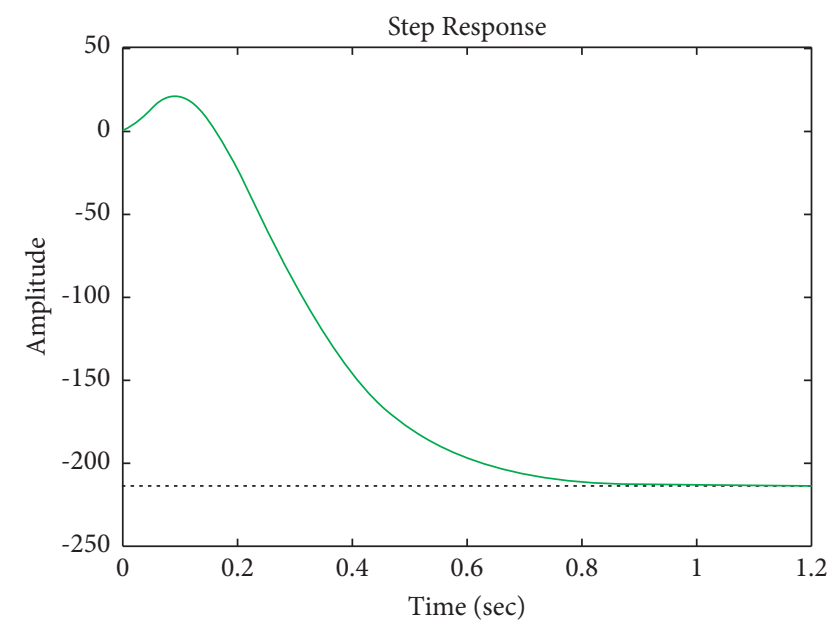

FIGURE 16: Step response of LQG regulator for the closed system “ $G_{4}(s) . "$

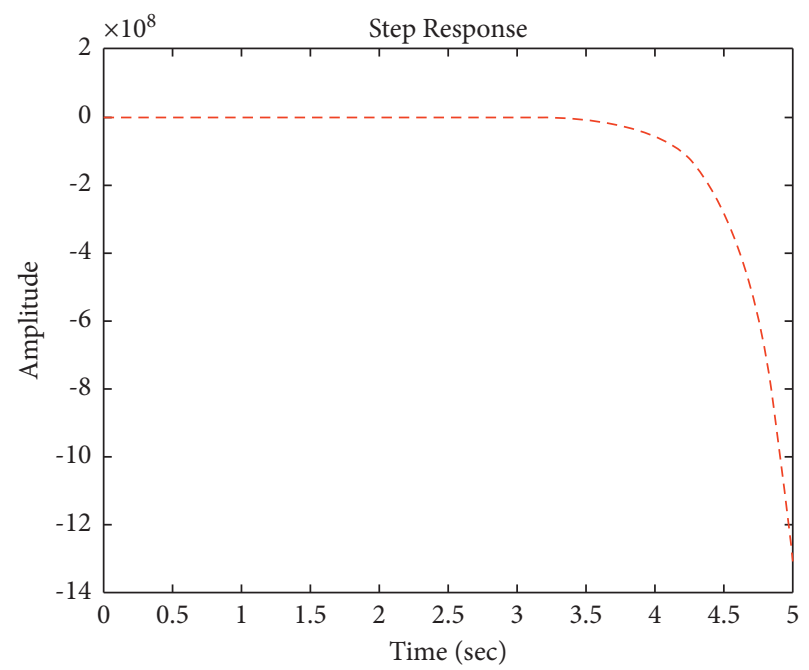

FIGURE 17: Step response of LQG regulator for the open system "G $G_{4}(s)$." 


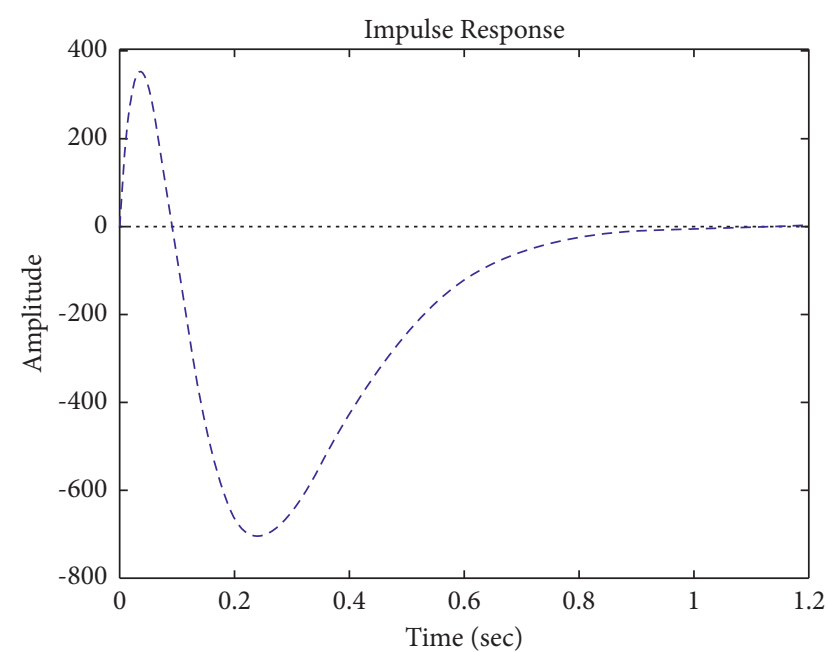

FIGURE 18: Impulse response of LQG regulator for the closed system " $G_{4}(s)$."

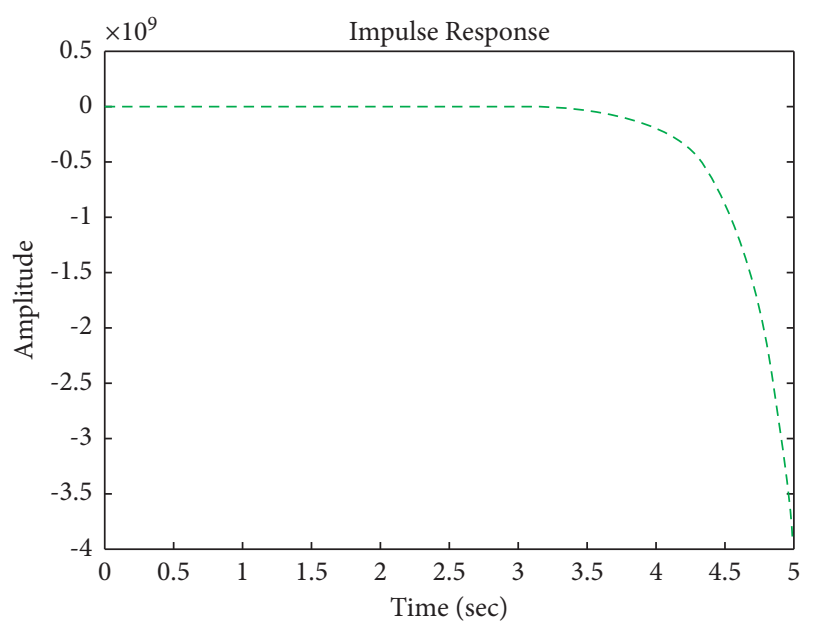

FIGURE 19: Impulse response of LQG regulator for the open system " $G_{4}(s)$."

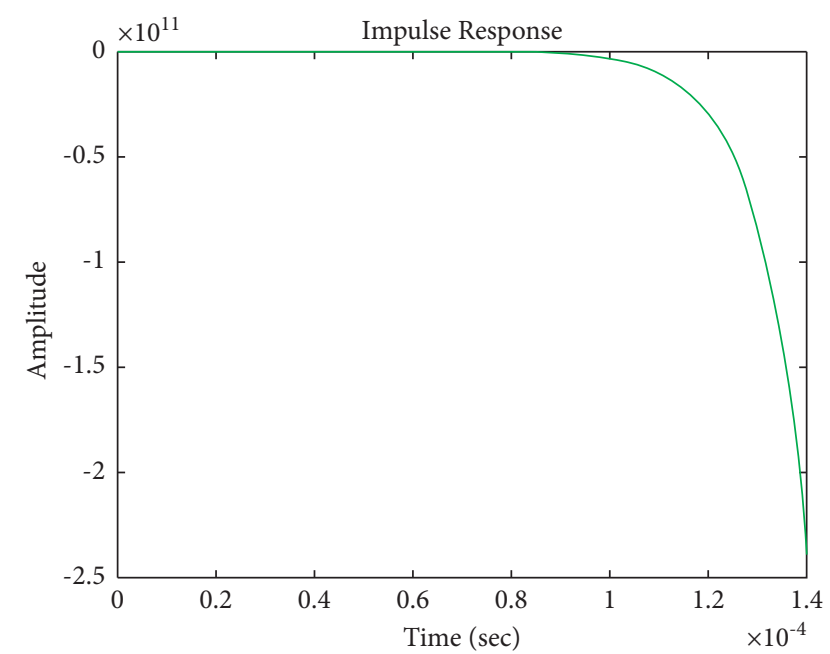

FIGURE 20: Impulse response of PID controller for the closed system “ $G_{1}(s)$."

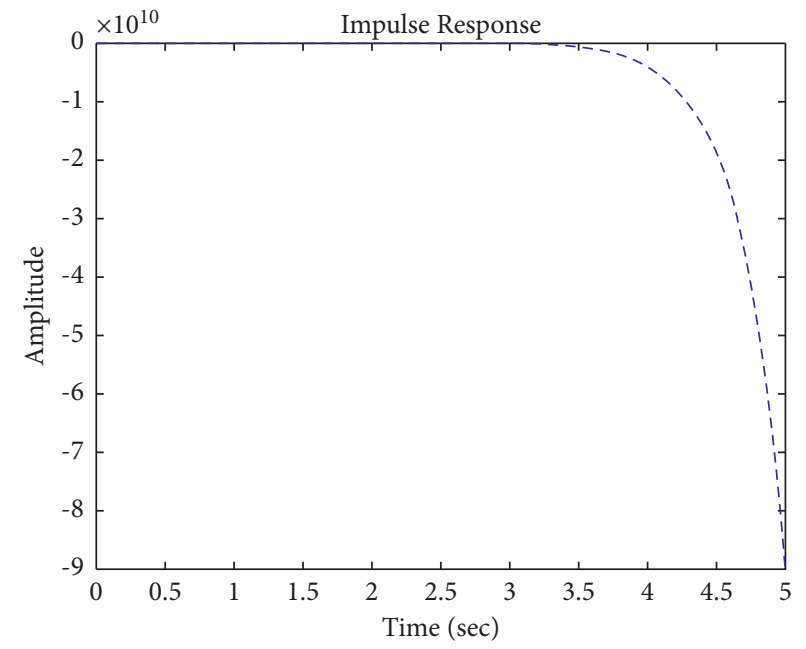

FIGURE 21: Impulse response of PID controller for the open system " $G_{1}(s) . "$

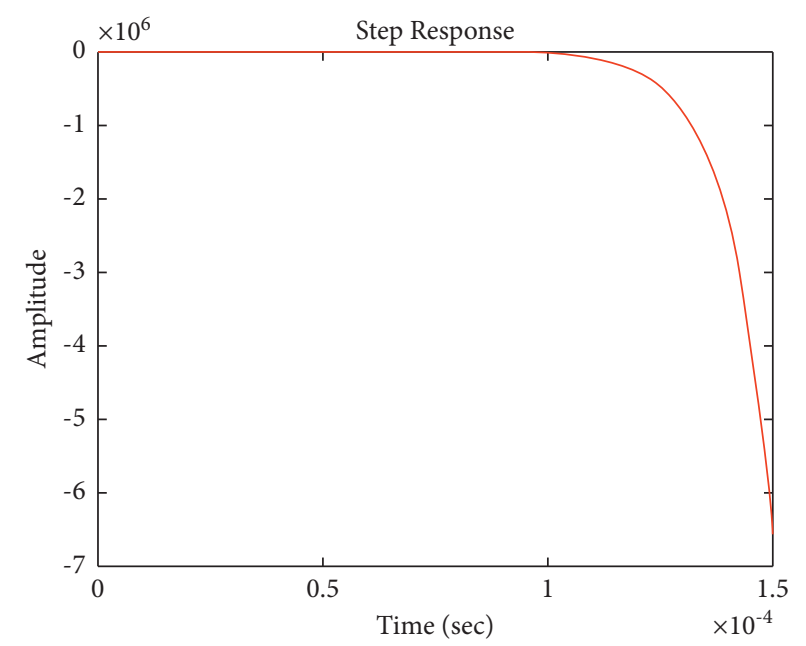

FIGURE 22: Step response of PID controller for the closed system " $G_{1}(s)$."

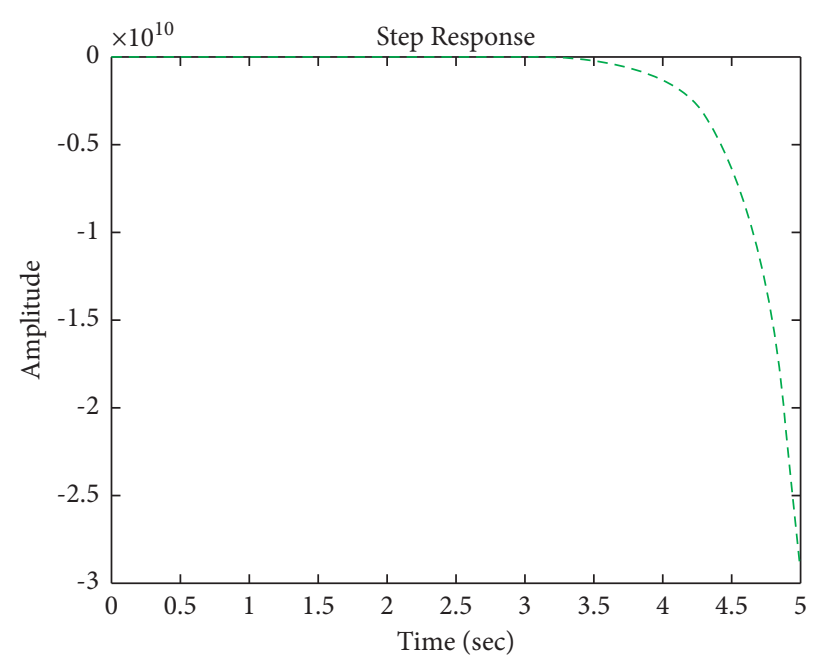

FIGURE 23: Step response of PID controller for the open system "G $G_{1}(s) . "$ 


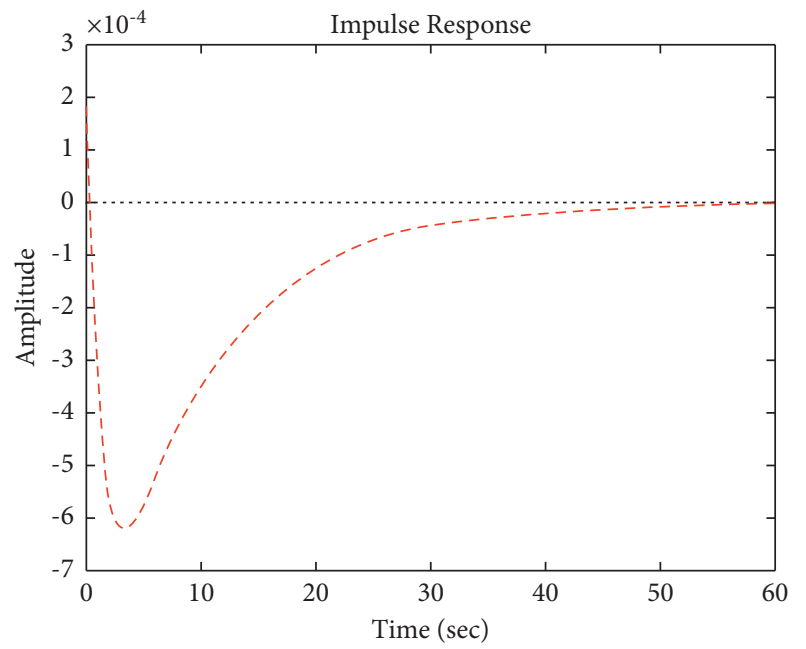

FIGURE 24: Impulse response of PID controller for the closed system " $G_{3}(s)$."

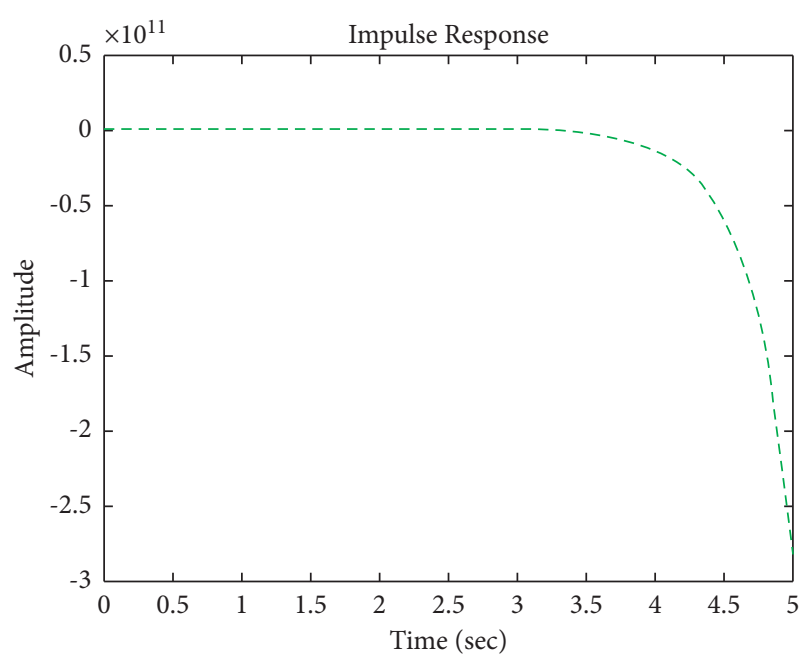

FIgURE 25: Impulse response of PID controller for the open system " $G_{3}(s)$."

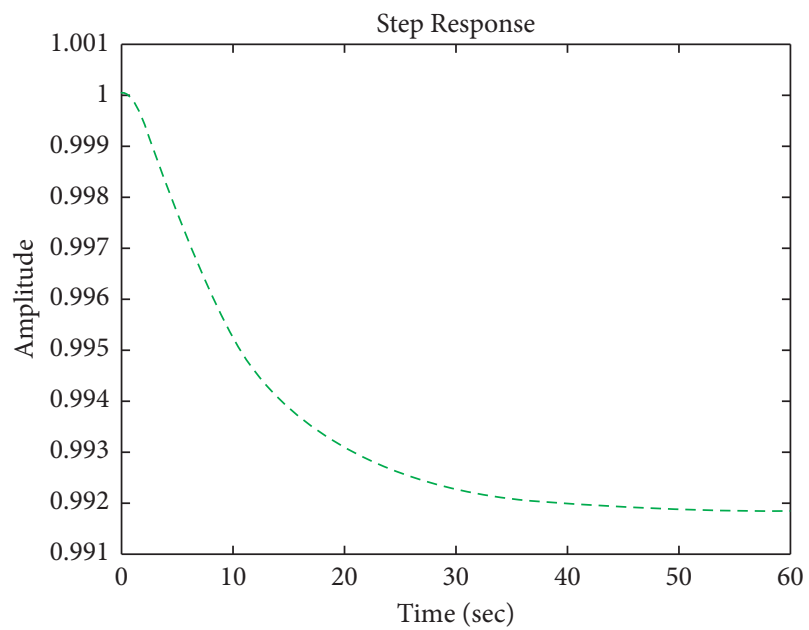

FIGURE 26: Step response of PID controller for the closed system " $G_{3}(s) . "$

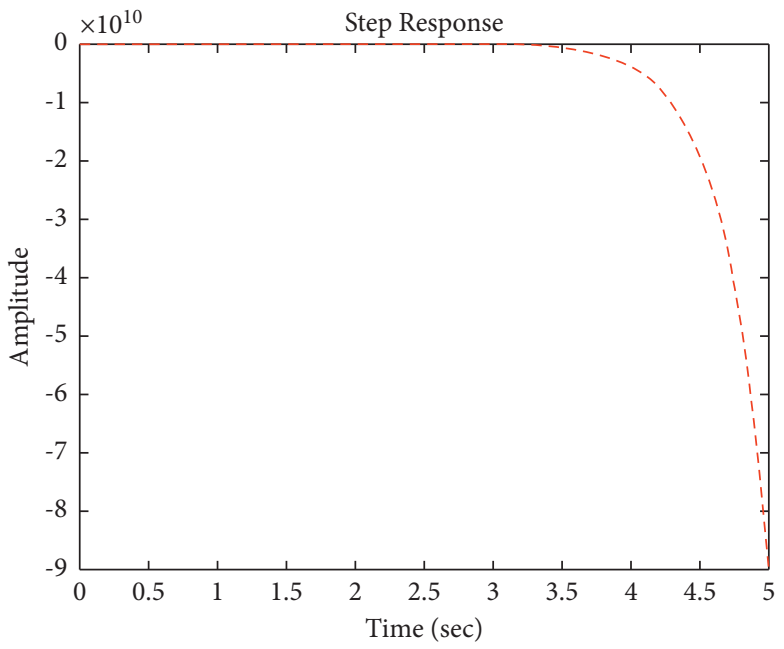

FIgURE 27: Step response of PID controller for the open system “ $G_{3}(s) . "$

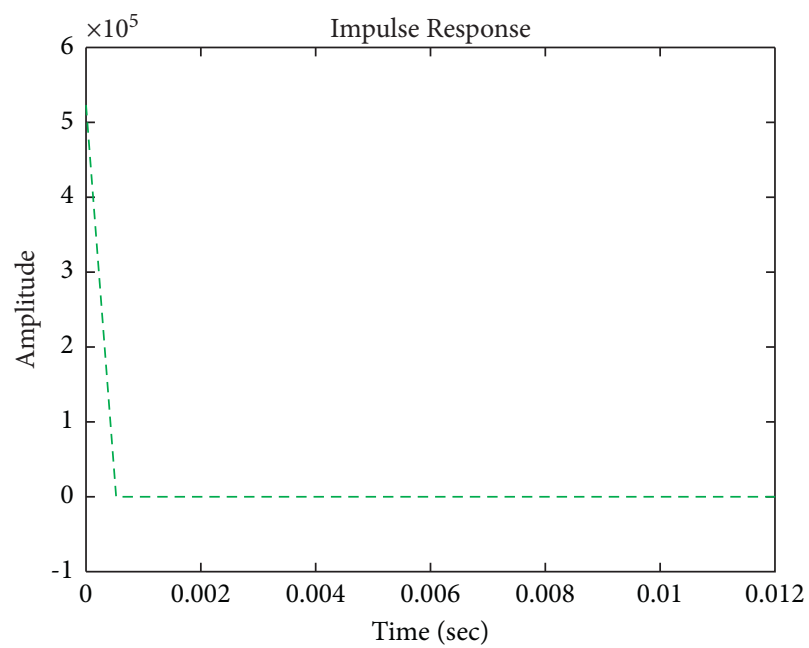

FIGURE 28: Impulse response of PID controller for the closed system “ $G_{2}(s)$."

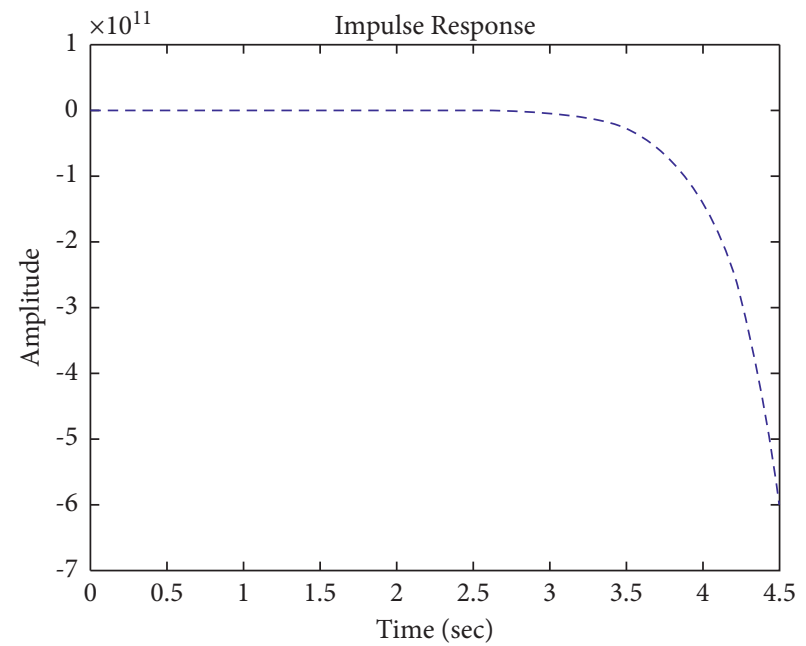

FIGURE 29: Impulse response of PID controller for the open system " $G_{2}(s)$." 


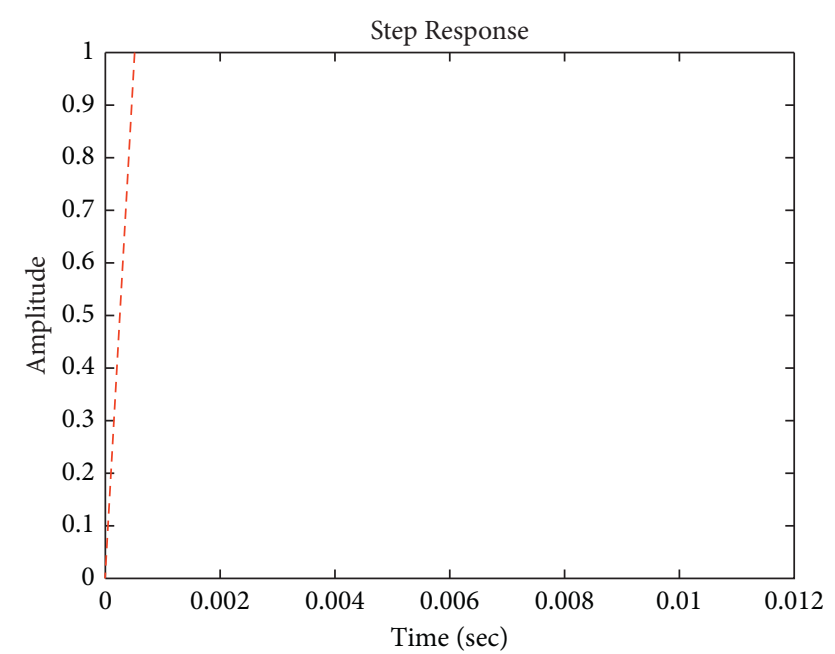

FIGURE 30: Step response of PID controller for the closed system " $G_{2}(s)$."

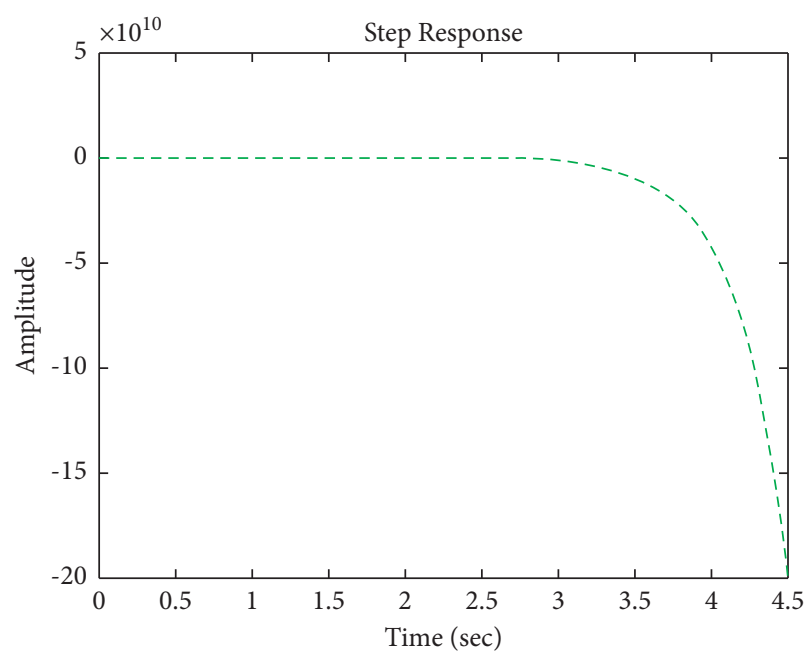

FIGURE 31: Step response of PID controller for the open system “ $G_{2}(s)$."

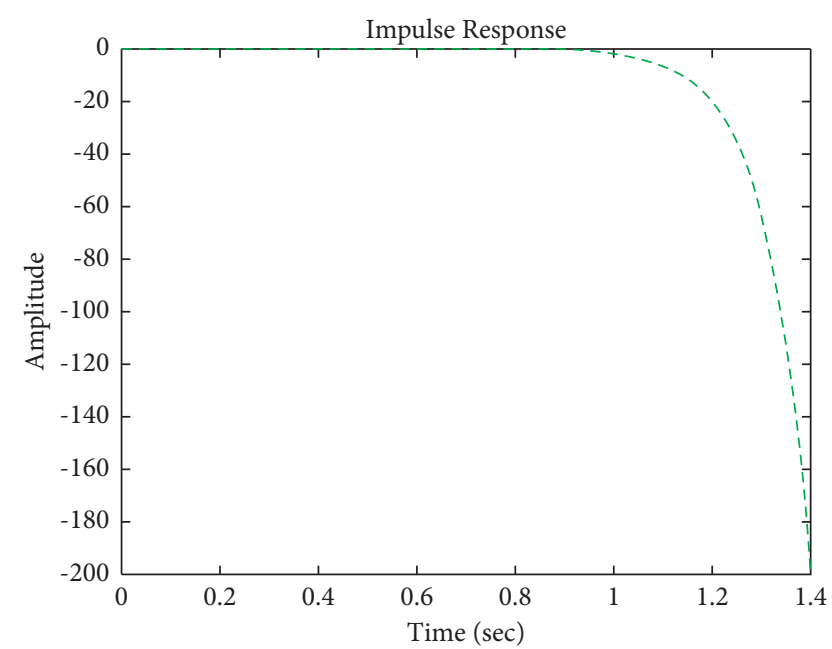

FIgURE 32: Impulse response of PID controller for the closed system " $G_{4}(s)$."

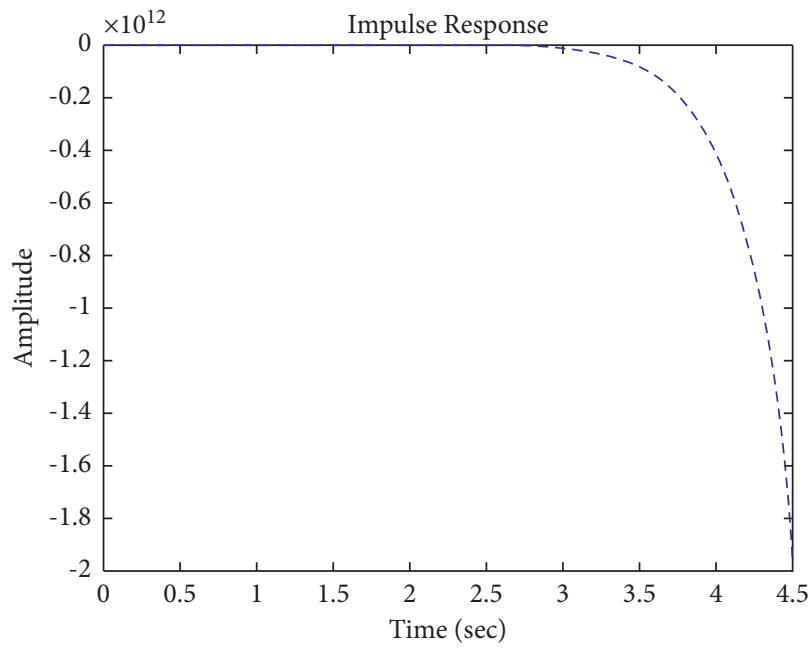

FIGURE 33: Impulse response of PID controller for the open system " $G_{4}(s)$."

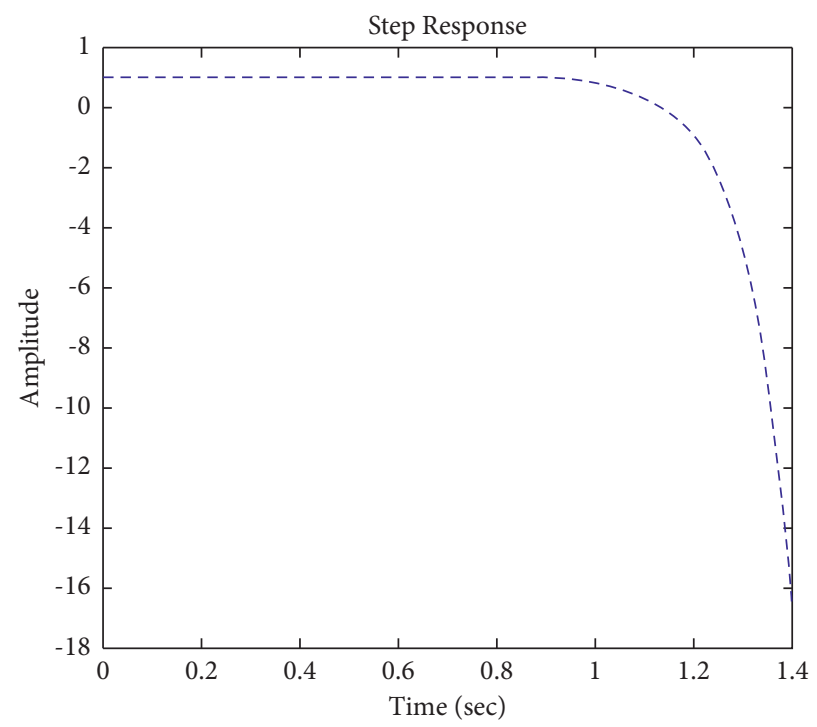

Figure 34: Step response of PID controller for the closed system " $G_{4}(s)$."

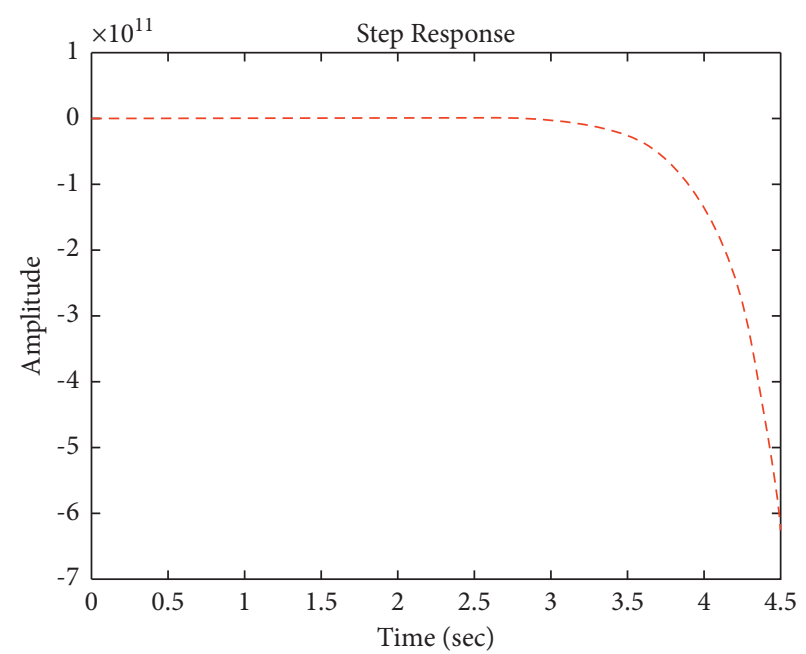

FIgURE 35: Step response of PID controller for the open system " $G_{4}(s)$." 


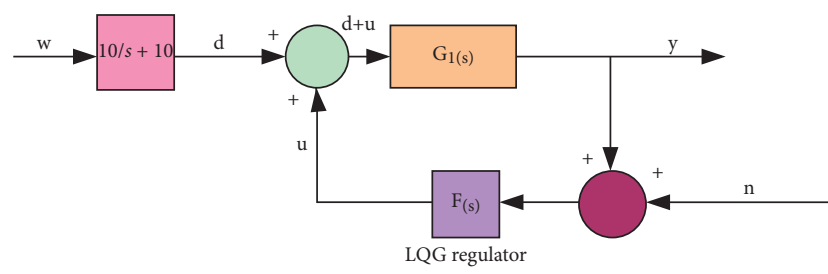

Figure 36: LQG regulator for $G_{1}(s)$.

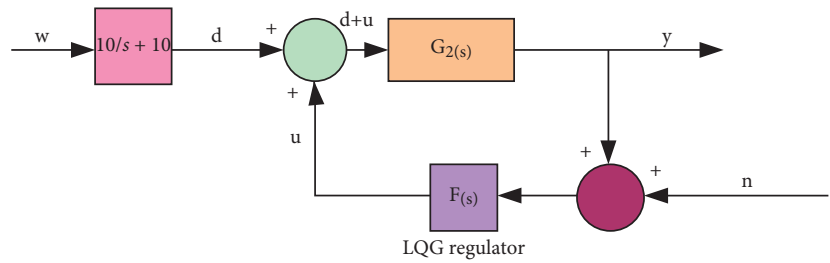

FIGURE 37: LQG regulator for $G_{2}(s)$.

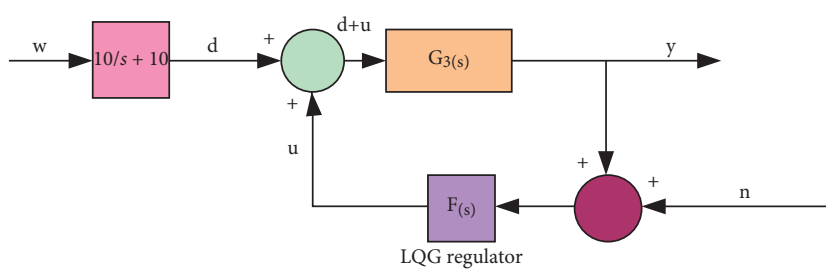

FIGURE 38: LQG regulator for $G_{3}(s)$.

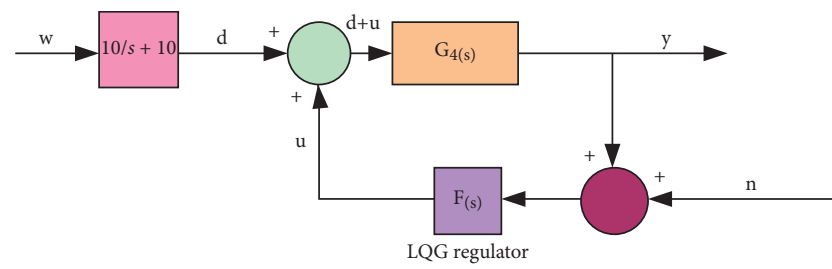

FIgURE 39: LQG regulator for $G_{4}(s)$.

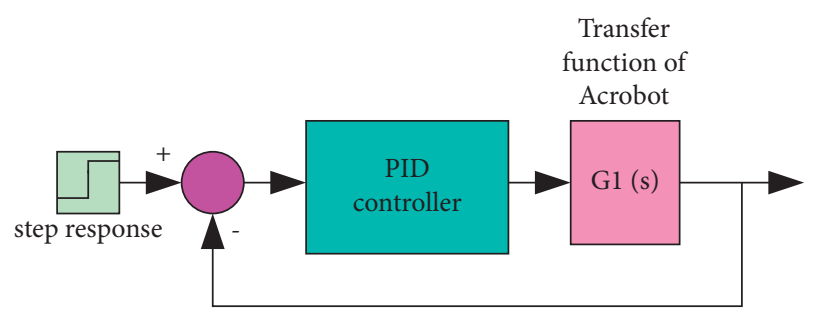

FIGURE 40: PID controller for $G_{1}(s), K_{p}=506.71, K_{i}=46.1$, and $K_{d}=562.44$.

The impulse response for the closed system (highlighted in blue in Figure 18) is better than that for the open system (highlighted in green in Figure 19). The value of amplitude of the oscillation of the closed system in this case is zero, and the closed system reaches a steady state. For this type of regulator, the closed system responds well. The value of

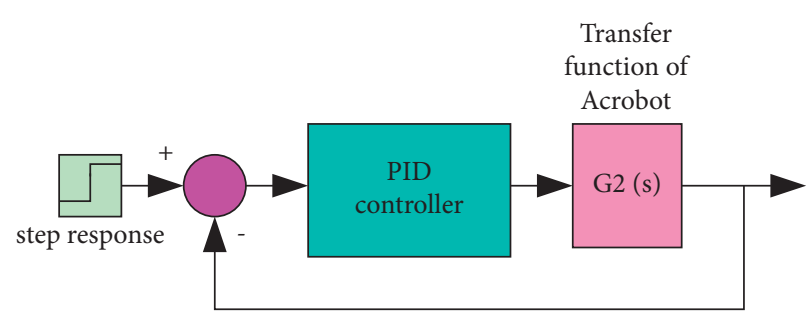

FIgURE 41: PID controller for $G_{2}(s), K_{p}=506.71, K_{i}=46.1$, and $K_{d}=562.44$.

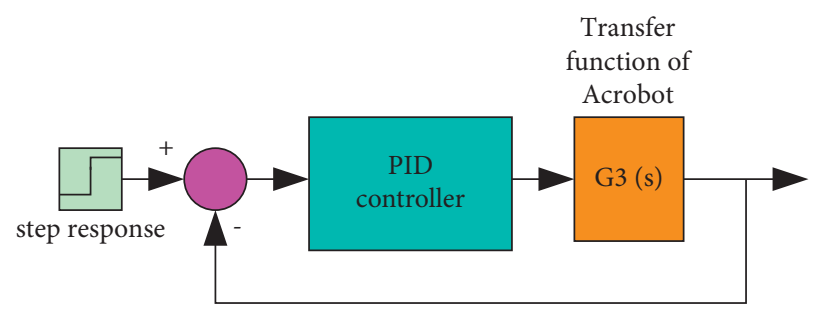

FIGURE 42: PID controller for $G_{3}(s), K_{p}=506.71, K_{i}=46.1$, and $K_{d}=562.44$.

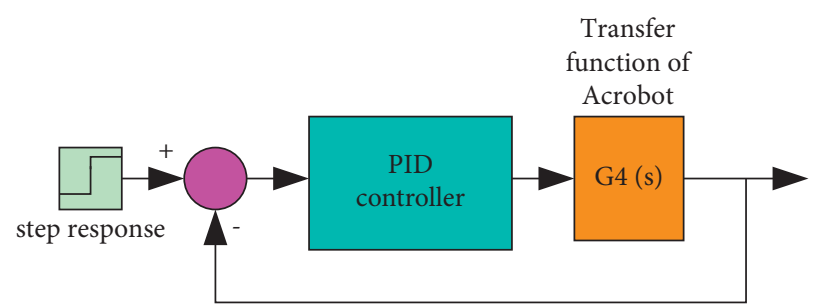

Figure 43: PID controller for $G_{4}(s), K_{p}=506.71, K_{i}=46.1$, and $K_{d}=562.44$.

amplitude of the oscillation of the open system in this case is large, and the open system does not reach a steady state.

The step response for the closed system (highlighted in green in Figure 16) is better than that for the open system (highlighted in red in Figure 17). The value of amplitude of the oscillation of the closed system in this case is -200 , and the closed system reaches a steady state. For this type of regulator, the closed system responds well. Meanwhile, the open system cannot respond well. In general, for a regulator of this type, the system responds well to the presence of noisy signals.

The impulse response for the closed system (highlighted in green in Figure 20) is worse than that for the open system (highlighted in blue in Figure 21). The value of amplitude of the oscillation of the closed system in this case is large, and the closed system does not reach a steady state. For this type of regulator, the closed system does not respond well. The value of amplitude of the oscillation of the open system in this case is large, and the open system does not reach a steady state.

The step response for the closed system (highlighted in red in Figure 22) is better than that for the open system (highlighted in green in Figure 23). The value of amplitude of the oscillation of the closed system in this case is large, and 
the closed system does not reach a steady state. For this type of regulator, the closed system does not respond well. Meanwhile, the open system cannot respond well. In general, for a regulator of this type, the system does not respond well.

The impulse response for the closed system (highlighted in green in Figure 28) is better than that for the open system (highlighted in blue in Figure 29). The value of amplitude of the oscillation of the closed system in this case is zero, and the closed system reaches a steady state. For this type of regulator, the closed system responds well. The value of amplitude of the oscillation of the open system in this case is large, and the open system does not reach a steady state.

The step response for the closed system (highlighted in red in Figure 30) is better than that for the open system (highlighted in green in Figure 31). The value of amplitude of the oscillation of the closed system in this case is 1.0, and the closed system reaches a steady state. For this type of regulator, the closed system responds well. Meanwhile, the open system cannot respond well. In general, for a regulator of this type, the system responds well.

The impulse response for the closed system (highlighted in red in Figure 24) is better than that for the open system (highlighted in green in Figure 25). The value of amplitude of the oscillation of the closed system in this case is zero, and the closed system reaches a steady state. For this type of regulator, the closed system responds well. The value of amplitude of the oscillation of the open system in this case is large, and the open system does not reach a steady state.

The step response for the closed system (highlighted in green in Figure 26) is better than that for the open system (highlighted in red in Figure 27). The value of amplitude of the oscillation of the closed system in this case is 0.992, and the closed system reaches a steady state. For this type of regulator, the closed system responds well. Meanwhile, the open system cannot respond well. In general, for a regulator of this type, the system responds well.

The impulse response for the closed system (highlighted in green in Figure 32) is better than that for the open system (highlighted in blue in Figure 33). The value of amplitude of the oscillation of the closed system in this case is large, and the closed system does not reach a steady state. For this type of regulator, the closed system does not respond well. The value of amplitude of the oscillation of the open system in this case is large, and the open system does not reach a steady state.

The step response for the closed system (highlighted in blue in Figure 34) is better than that for the open system (highlighted in red in Figure 35). The value of amplitude of the oscillation of the closed system in this case is large, and the closed system does not reach a steady state. For this type of regulator, the closed system does not respond well. Meanwhile, the open system cannot respond well. In general, for a regulator of this type, the system does not respond well.

The efficiency of the above control methods is in the following descending order:
(A) LQG regulator
(B) PID controller

\section{Conclusions}

LQG regulator in the case of interference signals affecting this system has been proposed in this study. Simulation shows positive results. This allows the closed system to reach steady state in a short time. At the same time, it also helps the open system to reach steady state in half the time compared to the closed system at the beginning of the operating cycle of the system. Although the steady state is achieved, simulation results of this type of regulator are only true in the case where the link angle between link 1 and link 2 is small compared to the equilibrium point. To widen the link angle between link 1 and link 2, further studies can be conducted in the future.

\section{Data Availability}

The data used to support the findings of this study are included within the article.

\section{Conflicts of Interest}

The author declares that there are no conflicts of interest.

\section{References}

[1] P. V. Gopi Krishna Rao, M. V. Subramanyam, and K. Satyaprasad, "Performance comparison of PID controller tuned using classical and genetic algorithm methods," International Journal of Applied Engineering Research ISSN 0973-4562, vol. 6, no. 14, pp. 1757-1766, 2011.

[2] M. Papoutsidakis, D. Piromalis, F. Neri, and M. Camilleri, "Intelligent algorithms based on data processing for modular robotic vehicles control," WSEAS Transactions on Systems, vol. 13, 2014.

[3] H. T. Nguyen, M. T. Nguyen, V. D. H. Nguyen, T. T. Doan, and C. P. Vo, "Designing PID-fuzzy controller for pendubot system," Robotica \& Management, vol. 22, no. 2, pp. 8-12, 2017.

[4] A. Ramm and M. Sjöstedt, Reaction Wheel Balanced Robot, Design and Sensor Analysis of Inverted Pendulum Robot, Digitala Vetenskapliga Arkivet, Stockholm, Sweden, 2015.

[5] J. Doyle, "Guaranteed margins for LQG regulators," IEEE Transactions on Automatic Control, vol. 23, no. 4, pp. 756-757, 1978.

[6] J. Doyle and G. Stein, "Robustness with observers," IEEE Transactions on Automatic Control, vol. 24, no. 4, pp. 607-611, 1979.

[7] J. B. Moore, D. Gangsaas, and J. Bright, "Performance and robustness trades in LQG regulator design," in Proceedings of the 20th IEEE Conference on Decision and Control, pp. 1191-1200, San Diego, CA, USA, December 1981.

[8] N. Lehtomaki, N. Sandell, and M. Athans, "Robustness results in linear quadratic gaussian based multivariable control design," IEEE Transactions on Automatic Control, vol. 26, no. 1, pp. 75-93, 1981.

[9] A. N. Madivale and D. E. Williams, "Some extensions of loop transfer recovery," in Proceedings of the: Proceedings of the American Control Conference, Boston, MA, USA, June 1985.

[10] J. Moore and L. Lige Xia, "Loop recovery and robust state estimate feedback designs," IEEE Transactions on Automatic Control, vol. 32, no. 6, pp. 512-517, 1987. 
[11] Z. Zhang and J. S. Freudenberg, "Loop transfer recovery with non-minimum phase zeros," in Proceedings of the 26th IEEE Conference on Decision and Control, Los Angeles, CA, USA, December 1987.

[12] G. Stein and M. Athans, "The LQG/LTE procedure for multivariable feedback design," IEEE Transactions on Automatic Control, vol. 32, no. 2, pp. 105-114, 1987.

[13] J. Doyle and G. Stein, "Multivariable feedback design: concepts for a classical/modern synthesis," IEEE Transactions on Automatic Control, vol. 26, no. 1, pp. 4-16, 1981.

[14] M. Safonov, A. Laub, and G. Hartmann, "Feedback properties of multivariable systems: the role and use of the return difference matrix," IEEE Transactions on Automatic Control, vol. 26, no. 1, pp. 47-65, 1981.

[15] E. Soroka and U. Shaked, "On the robustness of LQ regulators," IEEE Transactions on Automatic Control, vol. 29, no. 7, pp. 664-665, 1984.

[16] M. J. Grimble, "Optimal H-inf. robustness and the relationship to LQG design problems," International Journal of Control, vol. 43, no. 2, pp. 351-372, 1986.

[17] X. Gang and C. Guangzhong, "On the LQG and LQG/LTR methodology," in Proceedings of the 2000 International Workshop on Autonomous Decentralized System, Chengdu, China, September 2000.

[18] C. F. de Paula and L. H. C. de Ferreira, "An easy-to-use Hinf/ LTR control solution with mixed sensitivity properties," IEEE Transactions on Automatic Control, vol. 56, no. 7, pp. 17091713, 2011.

[19] L. R. Hosseini, D. Noll, and P. Apkarian, "On the generalization of LTR procedure," in Proceedings of the Chinese Control and Decision Conference, Hefei, China, May 2011.

[20] L. R. Hosseini, D. Noll, and P. Apkarian, An Extension of the LQG-LTR Procedure, Institut de Mathematiques de Toulouse, Toulouse, France, 2011.

[21] M. Girault and E. Videcoq, "Temperature regulation and tracking in a MIMO system with a mobile heat source by LQG control with a low order model," Control Engineering Practice, vol. 21, no. 3, pp. 333-349, 2013.

[22] L. Kumar, P. Kumar, and S. S. Dhillon, "A multiobjective optimization approach for linear quadratic gaussian/loop transfer recovery design," Optimal Control Applications and Methods, vol. 41, no. 4, pp. 1267-1287, 2020.

[23] T. Ishihara and L. A. Zheng, "Reduced-order LQG/LTR procedure for the plant output side," Optimal Control Applications and Methods, vol. 40, no. 6, pp. 1104-1119, 2019.

[24] S. Abderrahmene, C. Mohamed, A. Mustapha, K. Abderrahmene, and H. Rachida, "LQGi/LTR controller with integrators and feedforward controller applied to a Twin Rotor MIMO System," Przeglad Elektrotechniczny, vol. 1, no. 4 , pp. $50-55$.

[25] P. J. Neeraj and P. N. Seema, "Control of twin rotor MIMO system using cross PID control technique," in Proceedings of the International Conference on Communication and Signal Processing, Chennai, India, April 2018.

[26] E. Prempain and A. Lecchini-Visintini, "Dynamic analysis of a twin rotor MIMO system and control design," in Proceedings of the 2018 UKACC 12th International Conference on Control (CONTROL), pp. 5-7, Sheffield, England, September 2018.

[27] R. Mascaró Palliser, R. Costa-Castelló, and G. A. Ramos, "Iterative learning control experimental results in twin-rotor Device," Mathematical Problems in Engineering, vol. 2017, Article ID 6519497, 12 pages, 2017.
[28] A. Zhang, J. She, X. Lai, and M. Wu, "Motion planning and tracking control for an acrobat base on a rewinding approach," Automatica, vol. 49, no. 1, pp. 278-284, 2013. 